\title{
Prognostic value of preoperative dynamic contrast-enhanced MRI perfusion parameters for high-grade glioma patients
}

\author{
Agne Ulyte $^{1}$ • Vasileios K. Katsaros ${ }^{2,3}$ • Evangelia Liouta ${ }^{3}$ - Georgios Stranjalis ${ }^{3}$. \\ Christos Boskos $^{3,4} \cdot$ Nickolas Papanikolaou $^{5} \cdot$ Jurgita Usinskiene $^{6,7} \cdot$ Sotirios Bisdas $^{8}$ (D)
}

Received: 3 May 2016 / Accepted: 16 August 2016/Published online: 29 October 2016

(C) The Author(s) 2016. This article is published with open access at Springerlink.com

\begin{abstract}
Introduction The prognostic value of the dynamic contrastenhanced (DCE) MRI perfusion and its histogram analysisderived metrics is not well established for high-grade glioma (HGG) patients. The aim of this prospective study was to investigate DCE perfusion transfer coefficient $\left(\mathrm{K}^{\text {trans }}\right)$, vascular plasma volume fraction $\left(\mathrm{v}_{\mathrm{p}}\right)$, extracellular volume fraction $\left(\mathrm{v}_{\mathrm{e}}\right)$, reverse transfer constant $\left(\mathrm{k}_{\mathrm{ep}}\right)$, and initial area under gadolinium concentration time curve (IAUGC) as predictors of progression-free (PFS) and overall survival (OS) in HGG patients.

Methods Sixty-nine patients with suspected anaplastic astrocytoma or glioblastoma underwent preoperative DCE-MRI scans. DCE perfusion whole tumor region histogram parameters, clinical details, and PFS and OS data were obtained.
\end{abstract}

Sotirios Bisdas

s.bisdas@uclh.nhs.uk

1 Faculty of Medicine, Vilnius University, Vilnius, Lithuania

2 Department of Advanced Imaging Modalities - CT and MRI, General Anticancer and Oncological Hospital "St. Savvas", Athens, Greece

3 Department of Neurosurgery, Evangelismos Hospital, University of Athens, Athens, Greece

4 Department of Radiation Oncology, General Anticancer and Oncological Hospital "St. Savvas", Athens, Greece

5 Department of Radiology, Centre for the Unknown, Champalimaud Foundation, Lisbon, Portugal

6 National Cancer Institute, Vilnius, Lithuania

7 Affidea Lietuva, Vilnius, Lithuania

8 Department of Neuroradiology, The National Hospital for Neurology and Neurosurgery, University College London Hospitals, Box 65, Queen Square 8-11, London WC1N 3BG, UK
Univariate, multivariate, and Kaplan-Meier survival analyses were conducted. Receiver operating characteristic (ROC) curve analysis was employed to identify perfusion parameters with the best differentiation performance.

Results On univariate analysis, $\mathrm{v}_{\mathrm{e}}$ and skewness of $\mathrm{v}_{\mathrm{p}}$ had significant negative impacts, while $\mathrm{k}_{\mathrm{ep}}$ had significant positive impact on OS $(P<0.05) . \mathrm{v}_{\mathrm{e}}$ was also a negative predictor of PFS $(P<0.05)$. Patients with lower $\mathrm{v}_{\mathrm{e}}$ and IAUGC had longer median PFS and OS on Kaplan-Meier analysis $(P<0.05)$. $\mathrm{K}^{\text {trans }}$ and $\mathrm{v}_{\mathrm{e}}$ could also differentiate grade III from IV gliomas (area under the curve 0.819 and 0.791 , respectively).

Conclusions High $\mathrm{v}_{\mathrm{e}}$ is a consistent predictor of worse PFS and OS in HGG glioma patients. $\mathrm{v}_{\mathrm{p}}$ skewness and $\mathrm{k}_{\mathrm{ep}}$ are also predictive for OS. $\mathrm{K}^{\text {trans }}$ and $\mathrm{v}_{\mathrm{e}}$ demonstrated the best diagnostic performance for differentiating grade III from IV gliomas.

Keywords Dynamic contrast-enhanced MRI · Gliomas · Perfusion transfer coefficient · Vascular plasma volume fraction

\section{Introduction}

High-grade gliomas (HGGs) comprise a group of aggressive primary brain tumors with a heterogeneous prognosis: median survival time is around 1 year for glioblastoma [1], but $8 \%$ of patients survive up to 2.5 years or longer [2]. Until recently, WHO glioma grade has been considered the most robust prognostic factor, but this view is challenged by HGG genetic and imaging research [3-6]. Perfusion parameters, such as relative cerebral blood volume (rCBV), are among the most consistently recognized independent predictors of survival $[4,7]$. In line with the working hypothesis, perfusion parameters correlate with tumor vascularity and properties of vessels, which, in 
turn, are strongly associated with glioma grade progression and poorer survival $[8,9]$. Therefore, perfusion is viewed as a powerful prognostic tool to stratify gliomas according to their aggressiveness, predict patient survival, and eventually assist in treatment choice.

The most widely used MRI techniques to measure perfusion include dynamic susceptibility contrast-enhanced (DSC) and dynamic contrast-enhanced (DCE) perfusion. These two techniques have considerable differences. Firstly, DSC perfusion is based on T2* (susceptibilityweighted) signal change in the presence of contrast material, while DCE perfusion is calculated from $\mathrm{T} 1$ signal change due to contrast enhancement. Secondly, they yield different perfusion parameters. DSC primarily measures cerebral blood volume (CBV) and is therefore concerned with quantity of vascularization. In contrast, DCE perfusion describes the quality of vessels and quantifies parameters related to contrast extravasation-vascular permeability (leakiness). Increased blood vessel permeability is a cardinal feature of neoangiogenesis and is reflected in increased contrast transfer rate, $\mathrm{K}^{\text {trans }}$. DCE perfusion also enables calculation of other parameters such as extracellular volume fraction $\left(\mathrm{v}_{\mathrm{e}}\right)$, reverse transfer rate $\left(\mathrm{k}_{\mathrm{ep}}\right)$, vascular plasma volume fraction $\left(\mathrm{v}_{\mathrm{p}}\right)$, and initial area under the gadolinium concentration time curve (IAUGC). These parameters provide additional information about physiological tumor properties and could afford independent insight about clinical tumor behavior, especially as DCE perfusion parameters were shown not to correlate with DSC [10] or diffusion parameters [11] closely. DCE perfusion parameters have already been demonstrated to be diagnostic for glioma grade [12-17] and correlate with several proxies of hypoxia like microvascular density [18, 19] and HIF-1 $\alpha$ and vascular endothelial growth factor (VEGF) expression [20]. DCE perfusion also has predictive value for treatment with neoangiogenesis inhibitors [21, 22] and chemoradiotherapy [23].

Thus far, research on the prognostic value of DCE perfusion for HGG patient survival has been scarce - only a few studies have been conducted [10, 20, 24-26], some of them presenting contradicting results [27], focusing mostly on $\mathrm{K}^{\text {trans }}$ and $\mathrm{v}_{\mathrm{p}}$, and some of them employing the hot-spot method, where only tumor regions with subjectively highest parameter values are analyzed. We set out to partially fill this knowledge gap with a larger study sample and a comprehensive whole tumor volume histogram analysis of more DCE-MRI pharmacokinetic modeling parameters. The aim of this study was to investigate DCE perfusion parameters $\left(K^{\text {trans }}, \mathrm{v}_{\mathrm{p}}, \mathrm{v}_{\mathrm{e}}, \mathrm{k}_{\mathrm{ep}}\right.$, and IAUGC) as independent predictors of progression-free survival (PFS) and overall survival (OS) in HGG patients. Secondary objectives were to examine DCE performance to differentiate glioma grade III from IV and other histological characteristics of gliomas.

\section{Materials and methods}

\section{Patient population}

This prospective study was approved by the Institutional Review Board, and permission was granted for the use of images and medical records. The study was compliant with the declaration of Helsinki. All relevant information about the examination and the study was thoroughly explained for the patients, and informed consent was obtained.

From October 2009 to March 2015, 69 patients (41 men, 28 women; median age 55 years; range $21-77$ years) with conventional or spectroscopic MRI findings suggestive for a primary high-grade glioma (either anaplastic astrocytoma or glioblastoma (GBM)) were enrolled in the study. Exclusion criteria were any prior brain tumors, tumor histology other than GBM or anaplastic astrocytoma, and lack of informed consent. All patients received DCE-MRI prior to maximal surgical resection to confirm tumor histology. $\mathrm{O}^{6}$ methylguanine-DNA methyltransferase (MGMT) promoter methylation status, isocitrate dehydrogenase (IDH) 1 and 2 mutation, and Ki67 immunostaining index (MIB-1) were also investigated. Clinical variables, such as age, sex, Karnofsky performance score, and ensuing treatment, were recorded. All patients were operated, and the majority also received adjuvant treatment-radiotherapy, chemotherapy, or combined therapy. Patients were treated according to the current ESMO Clinical Practice Guidelines [28-30] and were regularly followed up, including MR imaging post-operatively, 3 weeks, 2, 3, 6, and 12 months after chemotherapy initiation, and biannually afterward, until there was evidence of clinical deterioration as defined by radiologic tumor progression, neurological deterioration, or death. Radiologic progression was defined according to the updated response assessment (RANO) criteria for high-grade gliomas encountering also the time from initial chemotherapy as described by Wen et al. [31].

\section{MR imaging}

All MR imaging examinations were performed using the same 1.5T scanner (MAGNETOM Avanto, Siemens Healthcare, Erlangen, Germany) with a 12-channel-array head coil. The imaging protocol included axial FLAIR images (repetition time/echo time (TR/TE) 9000/94 ms, inversion time (TI) $2500 \mathrm{~ms}$, slice thickness $4 \mathrm{~mm}$, intersection gap $10 \%$, fieldof-view $220 \times 220 \mathrm{~mm}$ ) and distortion-corrected T1-weighted images before and after contrast agent administration (TR/TE $275 / 2.5 \mathrm{~ms}$, slice thickness $4 \mathrm{~mm}$, intersection gap $10 \%$, fieldof-view $230 \times 230 \mathrm{~mm}$ ). All DCE-MRI studies were performed using a 3D fast low angle shot (FLASH) sequence optimized in temporal and spatial resolution in order to provide adequate anatomical coverage, with the following 
parameters: TR/TE $4 / 1.4 \mathrm{~ms}$, flip angle $15^{\circ}$, temporal resolution $6 \mathrm{~s}$, base resolution 128 , phase resolution $100 \%$, slice resolution $100 \%, 23$ slices, slice thickness $4 \mathrm{~mm}$, field-ofview $220 \times 220 \mathrm{~mm}$, GRAPPA factor 2, and total acquisition time $5 \mathrm{~min}$. T1 mapping was used to convert signal intensity into gadolinium concentration. The T1 map was calculated from precontrast multiple flip angle images $\left(6^{\circ}, 12^{\circ}\right.$, and $15^{\circ}$, each acquisition $1 \mathrm{~min}$ ) with otherwise similar acquisition parameters. Tumors were always situated in the center of the imaging volume; therefore, the difference between nominal and effective flip angles was assumed to be negligible. The gadobutrol administration $(0.1 \mathrm{mmol} / \mathrm{kg} /$ body weight $)$ was done with a flow rate of $4 \mathrm{ml} / \mathrm{s}$ using a power injector, followed by saline flush.

\section{Image processing and analysis}

The conventional and DCE-MR images were consensually reviewed by the same two board-certified neuroradiologists (V.K., S.B.) with experience in central nervous system tumor imaging. The whole tumor volumes were off-line manually delineated in T1 contrast-enhanced images. The DCE-MR images were transferred for post-processing to an off-line workstation running commercially available Olea Sphere ${ }^{\mathrm{TM}}$ software, version 2.3 (Olea Medical ${ }^{\mathrm{TM}}$, La Ciotat, France). Post-processing included motion correction and rigid-body model registration of precontrast dynamic MR images for conversion of signal intensities into gadolinium concentration. Visual verification and adjustment were used to check and correct any misalignment in the auto-registered images. Briefly, the software analyses transport processes by an open two-compartment model to describe the tissue concentration of the administered contrast agent: a central compartment representing the central blood pool and a peripheral compartment describing the tissue distribution volume $\left(\mathrm{v}_{\mathrm{e}}\right)$. The software provides the distribution volume of contrast agent in the tissue: $v_{\mathrm{e}}$ (extracellular volume fraction), the tracer exchange between the compartments: $\mathrm{K}^{\text {trans }}$ based on a modified ToftsKermode model, vascular plasma volume fraction: $\mathrm{v}_{\mathrm{p}}$, and also calculates IAUGC in $60 \mathrm{~s}$ [32]. Reverse transfer rate constant $\mathrm{k}_{\mathrm{ep}}$ is calculated as the ratio of $\mathrm{K}^{\text {trans }}$ over $\mathrm{v}_{\mathrm{e}}$. Deconvolution was computed by the standard singular value decomposition method. The arterial input function (AIF) region was selected manually on the right or left internal carotid artery $\mathrm{C} 4$ segment to yield the best fitting AIF curve. Internal carotid artery was chosen as basilar or middle cerebral arteries were not equally well visualized for all patients. AIF estimation was model-based and dose-scaled using a bi-exponential function $[33,34]$. The calculated DCE-MRI parameters have the following measurement units: $\mathrm{K}^{\text {trans }}$ in per minute; IAUGC in millimoles per second; $k_{e p}$ in per minute; $v_{p}$ dimensionless; and $\mathrm{v}_{\mathrm{e}}$ dimensionless [35].
A free, hand-drawn region of interest (ROI) was plotted around the contrast-enhancing tumor in the contrastenhanced T1-weighted images (paying attention to exclude any large vessels) or around the hyperintense tumor region on FLAIR images, if no contrast enhancement was observed. Tumor delineation and post-processing were performed by a board certified neuroradiologist (S.B.). Other tasks, not requiring qualitative evaluation, were performed by a student with 2 months of software experience (A.U.). The reviewers were blinded to follow up data. The post-processing was repeated in each slice containing tumor tissue, and the parameter values of all ROIs were exported into a spreadsheet. Only the successfully fitted voxels were included in the further analysis. The successful fitting was defined by the following criteria: all perfusion parameters non-negative, $0<\mathrm{K}^{\text {trans }}<4$, and $0<\mathrm{v}_{\mathrm{e}}$ $<1$. These arbitrary ranges were defined in order to automatically exclude any poorly fitted voxels with unrealistically high or negative values.

\section{Statistical analysis}

The primary outcomes of the study were OS, defined as the number of days from the date of the DCE-MRI examination until death or the last available follow-up date, and PFS, defined as the number of days until progression, verified clinically and by MR imaging, or until the last follow-up date, if no progression or death occurred. One-year PFS and OS were used as cutoffs to stratify patients and evaluate perfusion parameters as prognostic markers.

Data normality was examined by Kolmogorov-Smirnov test. Kurtosis and skewness were calculated for perfusion parameters. Two-sided independent samples Student $t$ test was performed for statistical testing of the differences between patient groups. Relations between different perfusion metrics were investigated using Pearson's product-moment correlations. Survival was analyzed using univariate and multivariate Cox regression analysis models. Receiver operating characteristic (ROC) curve analysis was used to investigate the prognostic value of different parameters for OS and PFS, as well as their diagnostic value for glioma grading and histopathological parameters (e.g., MGMT, IDH). Area under the curve (AUC) was computed, and the optimal cutoffs were calculated by selecting the highest Youden's J statistic on the ROC curve, thereby maximizing sensitivity and specificity. Kaplan-Meier curve analysis and log rank test were used to detect a difference of survival between patient groups, stratified according to perfusion and clinical parameters. Continuous variables are presented as means with standard deviation, discrete variables as medians with range. Maximum value, 90th percentile, skewness, and kurtosis of perfusion parameters were calculated and are denoted in the text by indices__max, _90, _skew, and _kurt, respectively. Results were declared statistically significant at the two-sided $5 \%$ comparison-wise significance level 
$(P<0.05)$. Statistical analysis was performed with SPSS version 22 (SPSS Inc., Chicago, IL, USA).

\section{Results}

\section{Patient data}

A total of 69 patients with high-grade gliomas were enrolled in the study. Within this group, $49(71 \%)$ of the tumors were grade IV (glioblastomas) and 20 (29\%) grade III (anaplastic astrocytomas). Median follow-up of the patients was 424 days (range 23-1686). During the follow-up period, 50 (72\%) patients experienced tumor progression; in $41(59 \%)$ cases, the progression occurred in less than 1 year after the DCE-MRI scan. Thirty-two (46\%) patients had died by the end of the study. Furthermore, $26 \%$ of the patients were positive for IDH mutation, $39 \%$ had methylated MGMT, and median MIB-1 was $20 \%$ (range $0-80 \%$ ). Twelve patients (17\%) received radiation therapy only, 3 (4\%) chemotherapy only, and 54 (78\%) combined chemotherapy and radiation therapy. The $22(32 \%)$ non-enhancing gliomas included 16 anaplastic astrocytomas (80\% of all grade III gliomas) and 6 GBMs (12\% of all GBMs). Examples of grade III and IV glioma DCE perfusion maps are shown in Fig. 1.

\section{Perfusion parameter descriptive statistics}

After excluding poorly fitted voxels from the histogram data, 2092 (median, range 88-17,590) voxels were analyzed per patient. The mean, median, standard deviation, and range of the maximum, 90th percentile, skewness, and kurtosis values of perfusion parameters of individual patients' histograms are summarized in Tables 1 and 2.

The average values of perfusion parameters were compared between patients stratified according to 1-year PFS and OS. For patients with less than 1-year PFS, $\mathrm{v}_{\mathrm{e} \_ \text {max }}(0.94 \pm 0.19$ vs. $0.77 \pm 0.42, P=0.044)$ and $\mathrm{v}_{\mathrm{e}} 90(0.41 \pm 0.37$ vs. $0.19 \pm 0.28$, $P=0.010)$ were significantly higher. There was no difference in the means of perfusion parameters for patients with less and more than 1-year OS ( $P>0.05$ for all perfusion parameters).

We also investigated whether perfusion parameters were different according to glioma histology. $\mathrm{K}_{\text {skew }}^{\text {trans }}$ IAUGC $_{90}$, IAUGC $_{\text {max }}, \mathrm{k}_{\text {ep } 90}, \mathrm{k}_{\text {ep max }}$, and $\mathrm{v}_{\mathrm{e}} 90$ were significantly different between grade III and IV gliomas (Tables 1 and 2). However, when only contrast-enhancing tumors were analyzed, no significant differences in $\mathrm{K}^{\text {trans }}$ and $\mathrm{v}_{\mathrm{e}}$ kurtosis and skewness could be identified between the grades. No perfusion parameters were significantly different for IDH-positive or methylated MGMT patient groups.

Non-enhancing tumors had significantly higher $\mathrm{K}^{\text {trans }}$ skewness $(P=0.004)$ and kurtosis $(P=0.047)$, as well as $\mathrm{v}_{\mathrm{e}}$ skewness $(P<0.001)$ and kurtosis $(P=0.001)$, compared to
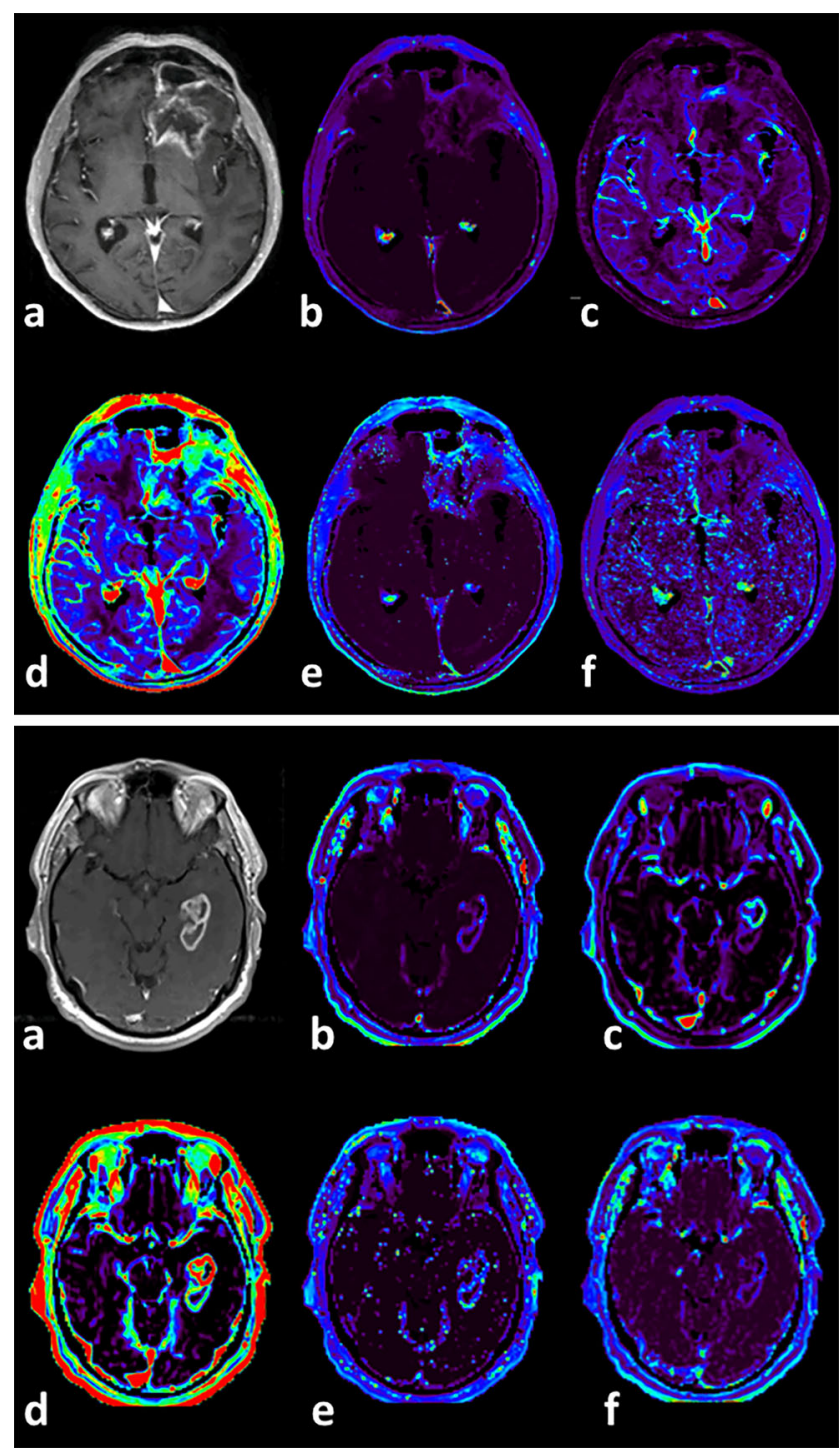

Fig. 1 DCE perfusion axial maps of grade III (above) and IV (below) gliomas. a T1 contrast-enhanced; b K ${ }^{\text {trans }} ; \mathbf{c ~}_{\mathrm{p}}$; d IAUGC; $\mathbf{e} \mathrm{v}_{\mathrm{e}} ; \mathbf{f ~ k}_{\mathrm{ep}}$ parameter maps

enhancing tumors. Non-enhancing tumors were also significantly more likely to be grade III than grade IV on chi-square test $(P<0.001)$.

\section{Univariate and multivariate survival analysis}

DCE perfusion, histology, and clinical parameters were analyzed as prognostic markers of PFS and OS with Cox proportional hazards model. Parameters that were significant in the univariate analysis and their associated hazard ratios are presented in Table 3.

\section{OS analysis}

In the univariate analysis of $\mathrm{OS}, \mathrm{v}_{\mathrm{e}-90}$ and $\mathrm{k}_{\mathrm{ep} \_90}$ were the most important significant prognostic factors (higher $\mathrm{v}_{\mathrm{e}}$ and lower 


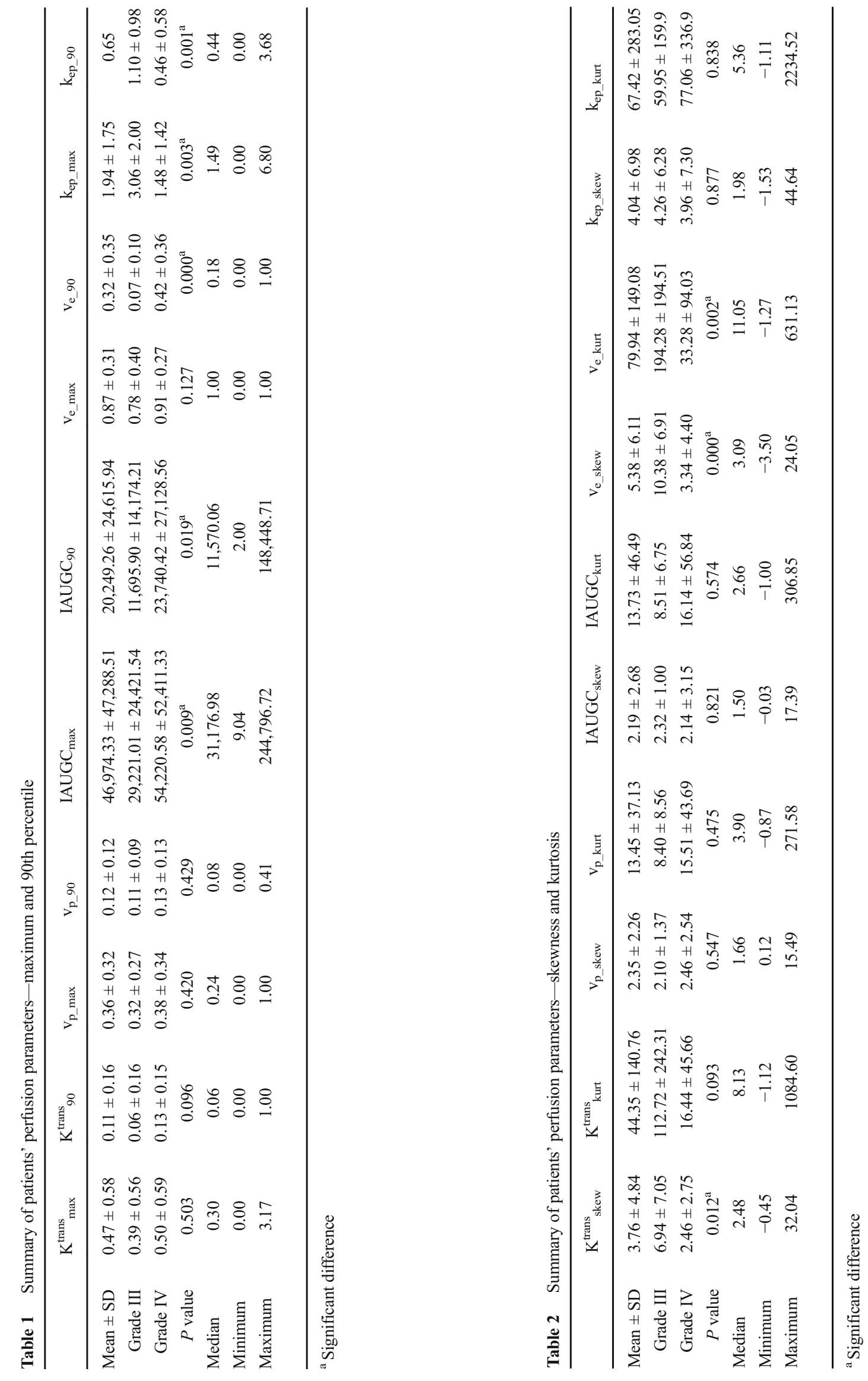


Table 3 Univariate analysis of significant prognostic perfusion and clinical parameters

\begin{tabular}{|c|c|c|c|c|c|c|}
\hline \multirow[b]{2}{*}{ Parameter } & \multicolumn{3}{|l|}{ OS } & \multicolumn{3}{|l|}{ PFS } \\
\hline & Hazard ratio (HR) & $95 \%$ confidence interval & $P$ value & Hazard ratio (HR) & $95 \%$ confidence interval & $P$ value \\
\hline Age & 1.06 & $1.02-1.09$ & 0.001 & 1.05 & $1.03-1.08$ & 0.000 \\
\hline Glioma grade & 7.15 & $1.71-29.97$ & 0.007 & 3.45 & $1.59-7.46$ & 0.002 \\
\hline KPS & 0.98 & $0.96-0.99$ & 0.007 & 0.98 & $0.97-1.00$ & 0.010 \\
\hline IDH & 0.16 & $0.04-0.69$ & 0.014 & 0.28 & $0.12-0.68$ & 0.005 \\
\hline $\mathrm{v}_{\mathrm{p}_{\text {_skew }}}$ & 1.18 & $1.03-1.35$ & 0.020 & 0.83 & $0.47-1.45$ & 0.512 \\
\hline $\mathrm{v}_{\mathrm{p} \_ \text {kurt }}$ & 1.01 & $1.00-1.02$ & 0.006 & 0.86 & $0.49-1.50$ & 0.599 \\
\hline $\mathrm{V}_{\mathrm{e} \_90}$ & 3.05 & $1.18-7.89$ & 0.021 & 2.69 & $1.22-5.94$ & 0.014 \\
\hline $\mathrm{V}_{\mathrm{e} \_ \text {skew }}$ & 0.93 & $0.86-1.01$ & 0.070 & 0.94 & $0.88-1.00$ & 0.035 \\
\hline $\mathrm{k}_{\mathrm{ep} \_90}$ & 0.46 & $0.21-0.98$ & 0.044 & 0.79 & $0.51-1.21$ & 0.277 \\
\hline
\end{tabular}

$\mathrm{k}_{\mathrm{ep}}$ were associated with poorer survival) (Table 3 ). $\mathrm{v}_{\mathrm{p} \_ \text {skew }}$ and $\mathrm{v}_{\mathrm{p} \_ \text {kurt }}$ were also prognostic, however, without significant hazard ratio (HR) values. Higher $\mathrm{v}_{\mathrm{e}}$ skew had a small negative nonsignificant impact on OS (HR 0.93, $95 \%$ CI 0.86-1.01; $P=0.070)$. Among the clinical and histological parameters, age ( $>55$ years), WHO tumor grade (GBM), Karnofsky performance score (KPS) (below $90 \%$ ), and absence of IDH1 or IDH1 mutation status were significant negative predictors of OS. On the contrary, MIB-1 and MGMT were not significant. Multivariate analyses were run for perfusion and histologicalclinical parameters. Glioma grade and patient age were not included in the models, as they rendered all other parameters insignificant. In the multivariate model including histological and clinical metrics, only KPS $(<90 \%)$ had a small negative impact on OS (HR 0.96, $95 \%$ CI 0.94-0.99; $P=0.012$ ). IDH, MIB-1, and MGMT status as well as the perfusion parameters did not reach statistical significance.

\section{PFS analysis}

One-year PFS univariate analysis yielded HRs comparable to those of OS. However, $v_{\mathrm{p} \_ \text {skew }}, \mathrm{v}_{\mathrm{p} \_ \text {kurt }}$, and $\mathrm{k}_{\mathrm{ep} \text { 90 }}$ did not reach significant level, while $\mathrm{v}_{\mathrm{e} \text { s skew }}$ became significant. Therefore, $\mathrm{v}_{\mathrm{e}} 90$ and $\mathrm{v}_{\mathrm{e} \text { skew }}$ were the only significant DCE perfusion predictors for 1-year PFS (Table 3). In a multivariate model including the significant predictors of univariate analysis-
KPS, IDH, $\mathrm{v}_{\mathrm{e} \_90}$, and $\mathrm{v}_{\mathrm{e} \_ \text {skew }}$-positive IDH (HR 0.27, $95 \%$ CI $0.10-0.73 ; P=0.010)$ and $v_{\mathrm{e}_{-} 90}(\mathrm{HR} 3.85,95 \%$ CL 1.35 $10.95 ; P=0.012$ ) remained significant predictors of PFS.

\section{Kaplan-Meier survival analysis}

For the Kaplan-Meier curve analysis, patients were stratified into groups below and above the median of the parameter analyzed (median values are presented in Tables 1 and 2). Perfusion parameters predicting significantly shorter PFS were high $\mathrm{v}_{\mathrm{e} \_90}, \mathrm{IAUGC}_{\max }$, and IAUGC $\mathrm{IO}_{90} \mathrm{~K}_{\max }^{\text {trans }}$ did not reach statistical significance for PFS prediction $(P=0.085)$, as well as $\mathrm{K}_{90}^{\text {trans }}(P=0.108)$. Significant prognostic factors for OS were $\mathrm{v}_{\mathrm{e} \_90}$ and IAUGC $\mathrm{C}_{90}$. Significantly different PFS and OS rates are presented in Tables 4 and 5. Kaplan-Meier survival curves for selected parameters are shown in Fig. 2.

\section{ROC curve analysis}

Perfusion parameters achieved weak to moderate prognostic performance for 1-year PFS. The highest AUC was demonstrated by $\mathrm{v}_{\mathrm{e}-90}(\mathrm{AUC}=0.70)$ and $\mathrm{IAUGC}_{90}(\mathrm{AUC}=0.66)$ (Fig. 3a).

ROC curve analysis was also performed to assess DCE perfusion as a tool to differentiate anaplastic astrocytoma and GBM. $\mathrm{K}_{90}^{\text {trans }}$ (AUC $=0.82$; optimal cutoff $0.02 \mathrm{~min}^{-1}$,

Table 4 Kaplan-Meier analysis for PFS

\begin{tabular}{|c|c|c|c|c|c|c|}
\hline \multirow[b]{2}{*}{ Parameter } & \multirow[b]{2}{*}{ Median value } & \multicolumn{2}{|l|}{ Above median } & \multicolumn{2}{|l|}{ Below median } & \multirow[b]{2}{*}{$P$ value } \\
\hline & & Median survival, days & $95 \%$ confidence interval & Median survival, days & $95 \%$ confidence interval & \\
\hline $\mathrm{v}_{\mathrm{e}-90}$ & 0.18 & 293 & $226-360$ & 541 & $398-684$ & 0.021 \\
\hline IAUGC $_{\max }$ & $31,176.98$ & 293 & $282-304$ & 541 & $297-790$ & 0.028 \\
\hline IAUGC $_{90}$ & $11,570.06$ & 293 & $282-304$ & 554 & $389-710$ & 0.016 \\
\hline
\end{tabular}


Table 5 Kaplan-Meier analysis for OS

\begin{tabular}{|c|c|c|c|c|c|c|}
\hline \multirow[b]{2}{*}{ Parameter } & \multirow[b]{2}{*}{ Median value } & \multicolumn{2}{|l|}{ Above median } & \multicolumn{2}{|l|}{ Below median } & \multirow[b]{2}{*}{$P$ value } \\
\hline & & Median survival, days & $95 \%$ confidence interval & Median survival, days & $95 \%$ confidence interval & \\
\hline $\mathrm{V}_{\mathrm{e}_{-} 90}$ & 0.18 & 436 & $315-557$ & 1058 & $537-1579$ & 0.024 \\
\hline IAUGC $_{90}$ & $11,570.06$ & 490 & $369-610$ & 868 & $612-1124$ & 0.040 \\
\hline
\end{tabular}

sensitivity 0.94 , specificity 0.70$)$ and $\mathrm{v}_{\mathrm{e}} 90$ (AUC $=0.79$; optimal cutoff 0.66 , sensitivity 0.76 , specificity 0.80 ) showed the best diagnostic value for histological staging (Fig. 3b).

\section{Discussion}

In this study, we found that $\mathrm{v}_{\mathrm{e}}$ was prognostic for PFS and OS in univariate analysis, in contrast to $\mathrm{K}^{\text {trans }}$, which had an independent role only in differentiating grade III from IV gliomas.
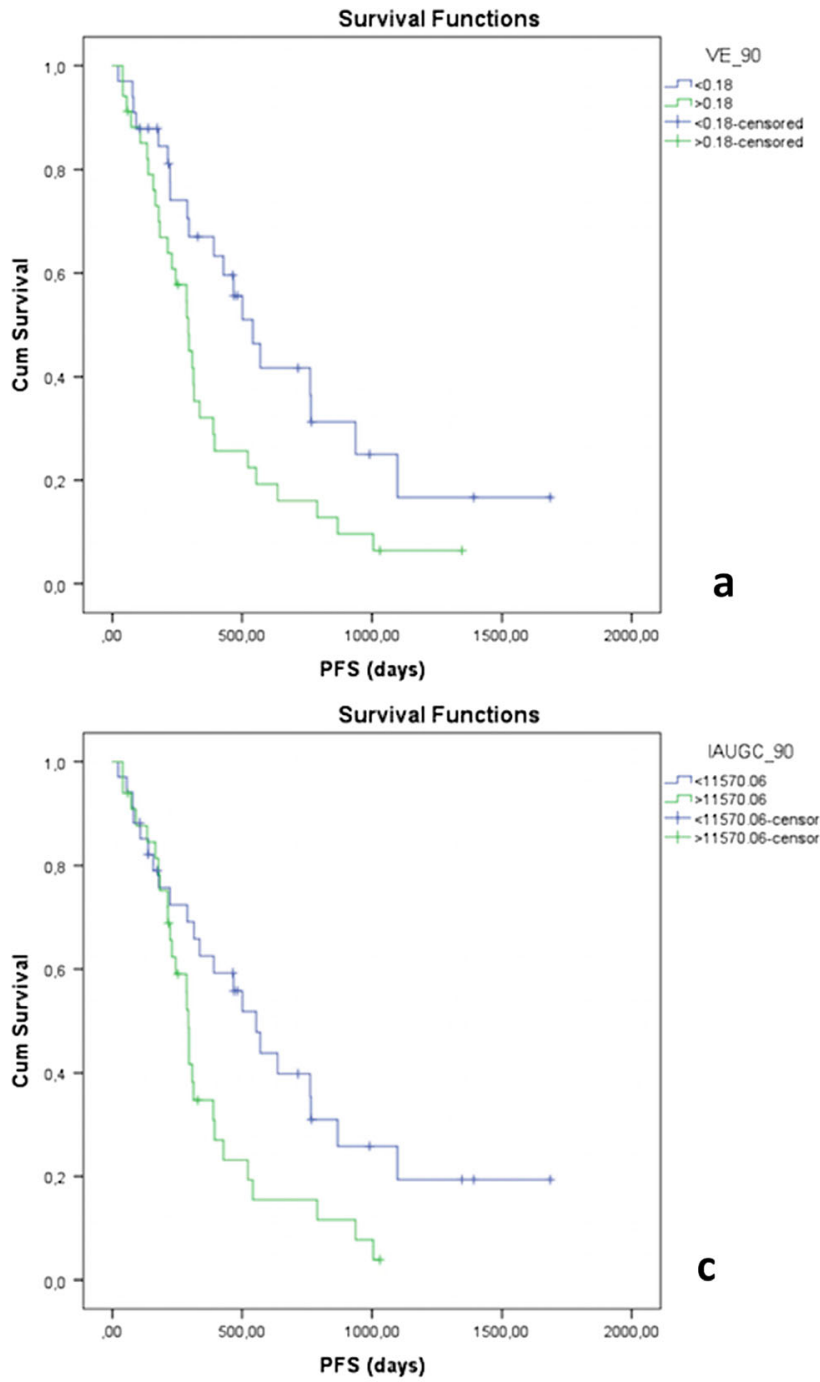

$\mathrm{k}_{\mathrm{ep}}$ was another predictor of OS, and it was also significantly different between grade III and IV gliomas. Histogram descriptors $-\mathrm{v}_{\mathrm{p}}$ skewness and kurtosis, and $\mathrm{v}_{\mathrm{e}}$ skewness - were significant predictors of OS, although the associated hazard ratios were modest.

Few studies have investigated DCE perfusion correlation with high-grade glioma patients' survival. Nguyen et al. [26] found both higher $\mathrm{K}^{\text {trans }}$ and $\mathrm{v}_{\mathrm{p}}$ to be associated with worse OS in a population of mixed grade II-IV astrocytomas, oligoastrocytomas, and oligodendrogliomas, using the hot-
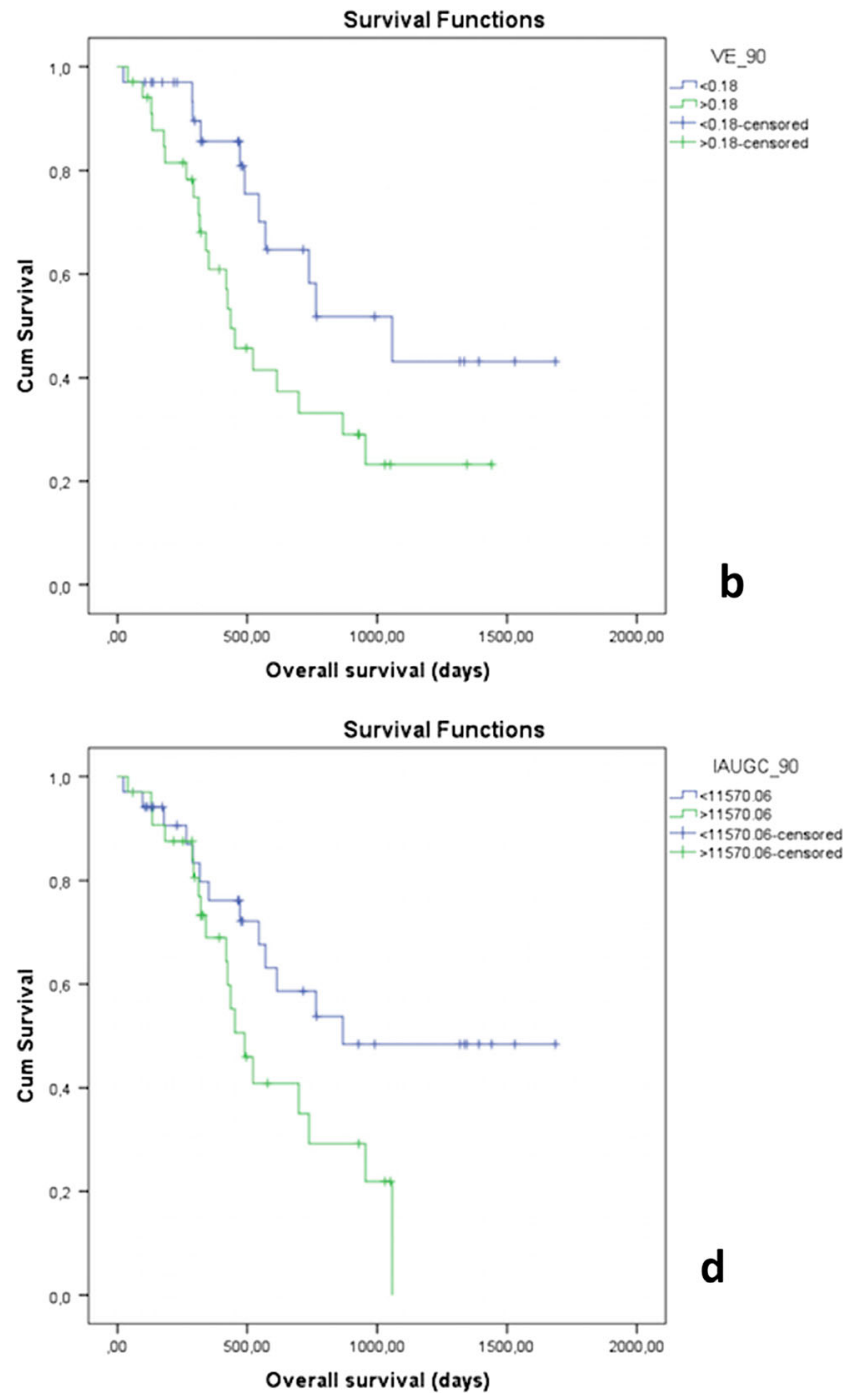

Fig. 2 a, b Kaplan-Meier curves of $\mathrm{v}_{\mathrm{e}} 90$ for PFS and OS; c, d Kaplan-Meier curves of IAUGC 90 for PFS and OS 

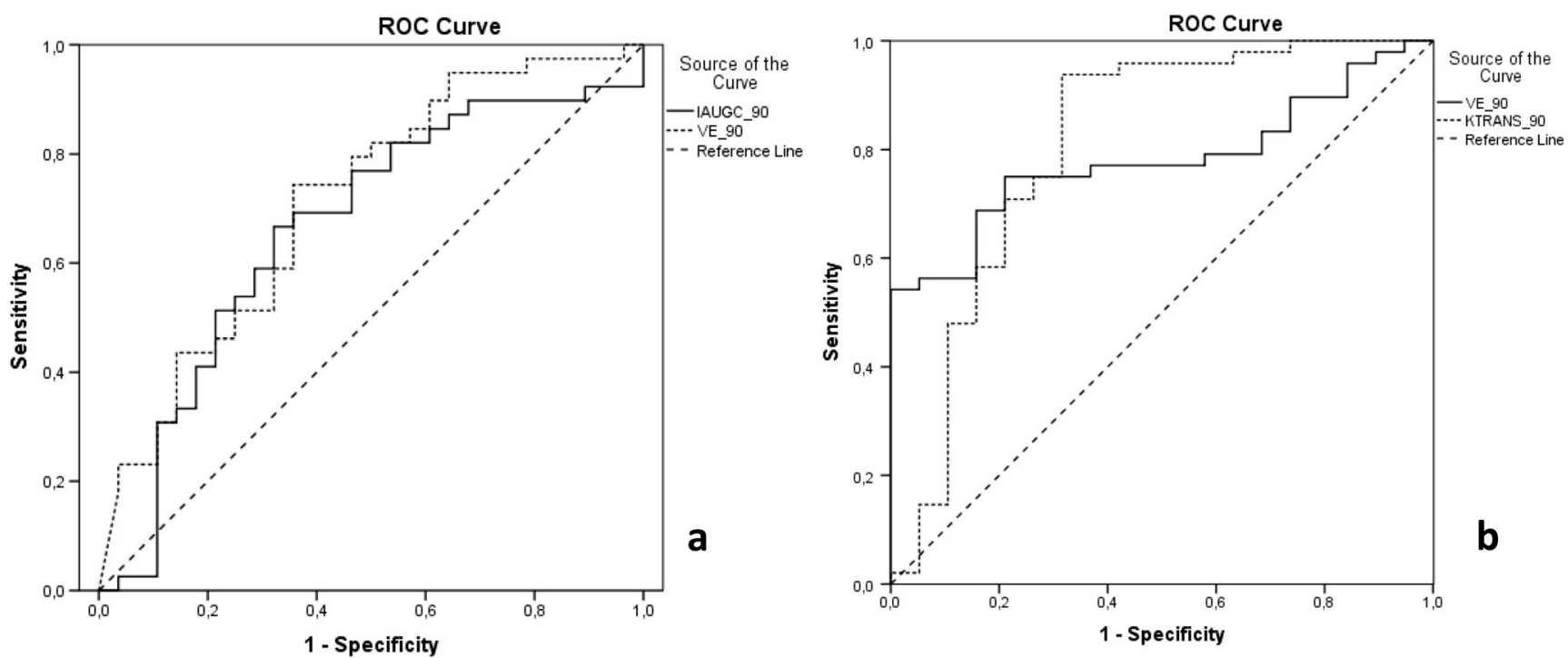

Fig. 3 ROC curve analysis. $\mathbf{a} \mathrm{v}_{\mathrm{e}} 90$ and IAUGC $_{90}$ for 1 -year PFS prognosis; $\mathbf{b} \mathrm{v}_{\mathrm{e}} 90$ and $\mathrm{K}^{\text {trans }}{ }_{90}$ for differentiation between anaplastic astrocytomas and GBM

spot ROI method. Bonekamp et al. [10] found $\mathrm{K}^{\text {trans }}$ to be independently associated with worse survival in a sample of 37 GBMs. Compared to DSC-calculated rCBV, $\mathrm{K}^{\text {trans }}$ was associated with a remarkably higher hazard ratio. Moreover, $\mathrm{K}^{\text {trans }}$ did not correlate with rCBV closely. In a sample of 18 mixed diagnosis glioma patients with GBMs, oligodendrogliomas, a meningioma, and brain tumors of other histology, Jensen et al. [20] found that $\mathrm{v}_{\mathrm{e}}$ of peritumoral edema correlates with OS, while blood volume $\mathrm{v}_{\mathrm{b}}$ correlates with PFS in active tumor regions, and, similar to our study, did not find $\mathrm{K}^{\text {trans }}$ to be a significant predictor of survival. Analyzing numerous histogram parameters of 61 glioblastomas, Choi et al. [24] found that $\mathrm{K}^{\text {trans }}$ and $\mathrm{v}_{\mathrm{e}}$ were associated with worse OS and PFS. Finally, Burth et al. [25] recently found the 90 th percentile of $\mathrm{K}^{\text {trans }}$ both at contrast-enhancing and edema parts of glioblastoma not to have significant prognostic value (interestingly, only the 90th percentile of rCBV of the contrast-enhancing part was a significant predictor of PFS from all imaging biomarkers investigated, leaving apparent diffusion coefficient (ADC) as insignificant as well).

Our study differed from the aforementioned ones in a number of aspects. We have included only astrocytomas (anaplastic and GBM) to have a more homogeneous sample, as oligodendrogliomas are known to have different perfusion characteristics, which could bias DCE perfusion analysis $[36,37]$. We used histogram analysis instead of the hot-spot ROI maximum value method. Histogram analysis has been shown to be more reproducible [38] and also enables to calculate tumor voxel statistical distribution parameters: skewness and kurtosis. Until now, correlation of these DCE perfusion parameters and survival has been investigated minimally.

Lack of research on the other than $\mathrm{K}^{\text {trans }}$ parameters could be because only $\mathrm{K}^{\text {trans }}$ and IAUGC were originally recommended as the primary end points for perfusion studies [39]. However, even the correlation between $\mathrm{K}^{\text {trans }}$ and survival has not been firmly established as well. In an early study on the topic, Mills et al. [27] surprisingly found higher $\mathrm{K}^{\text {trans }}$ to result in longer survival. This trend is indeed observed in some non-brain tumors: metastatic renal cell carcinoma and possibly hepatocellular carcinoma treated with VEGF inhibitors [40], as well as head and neck squamous cell carcinoma treated with chemoradiation [41]. Higher $\mathrm{K}^{\text {trans }}$ is associated with prolonged OS presumably by enhanced drug delivery through more permeable capillaries in the tumor. However, subsequent glioma studies have shown the opposite trend. Gliomas with lower vascular permeability $\left(\mathrm{K}^{\text {trans }}\right)$ and a pronounced decrease of it on the course of treatment are associated with longer OS after chemotherapy [21] and radiation therapy [23, 42], although contradicting results have been published as well [43]. Vascular permeability, measured as $\mathrm{K}^{\text {trans }}$, could indirectly reflect oxygenation status and thereby predict the response to radiotherapy. It is also possible that lower permeability profile is prognostic rather than predictive and could be associated with better survival regardless of the treatment.

In our study, the most consistent predictor of survival, significantly higher in patients with less than 1-year PFS, and also a significant prognostic factor for PFS and OS in univariate analysis as well as in Kaplan-Meier analysis, was $\mathrm{v}_{\mathrm{e}}$. On multivariate analysis, only $\mathrm{v}_{\mathrm{e}}$ remained an independent prognostic factor for PFS. $v_{\mathrm{e}}$ represents the extracellular volume fraction or the leakage space, where the contrast agent accumulates after escaping from the intravascular compartment [44], and is thought to reflect the extravascular architecture of the tumor [39]. In preclinical studies, $\mathrm{v}_{\mathrm{e}}$ has been found to correspond well to the histological extracellular volume [45], 
coincide with histological necrosis and apoptosis [46], and correlate negatively with cellularity in glioma models [47]. Although extracellular volume could be expected to correlate with ADC, as both parameters reflect cellular density, direct correlation between $\mathrm{v}_{\mathrm{e}}$ and ADC was not found [11]. This suggests that current understanding of the exact physiologic meaning of $\mathrm{v}_{\mathrm{e}}$ might be incomplete. $\mathrm{v}_{\mathrm{e}}$ should not be seen strictly as space between cells and microvasculature/ macrovasculature but rather as a parameter in the applied model of the tracer kinetics, therefore subject to some constrains. The accurate estimation of $\mathrm{v}_{\mathrm{e}}$ is dependent on the flow and permeability of the tumor vasculature [48]. As the tracer traverses the vasculature, a large interstitial space $\mathrm{v}_{\mathrm{e}}$ would require a substantial amount of tracer to be extracted from the vascular space for the interstitial space to reach a steadystate concentration. For instance, if the flow is very high or $v_{p}$ is large relative to $\mathrm{v}_{\mathrm{e}}$, steady state could be approached relatively quickly in about 5-6 min, as the tracer traverses through the tissue largely within the vascular space. In this case, $v_{\mathrm{e}}$ estimation is reliable. However, tracer extraction (influx) into the interstitial space depends on the capillary permeability. If PS (permeability surface-area product) is low, tracer influx is slow and the corresponding contrast agent concentration curve in tissue approaches its steady-state concentration slowly. In that case, 5-6-min acquisition underestimates the real $\mathrm{v}_{\mathrm{e}}$. If PS is high, the tracer influx is high and in the given acquisition time (5 min in our study) $\mathrm{v}_{\mathrm{e}}$ estimation reflects partly this pathophysiology. Thus, the higher $\mathrm{v}_{\mathrm{e}}$ reflects fast tracer kinetics and is probably due to high permeability, a known biomarker of malignancy itself.

The mechanism on how $\mathrm{v}_{\mathrm{e}}$ is associated with tumor aggressiveness is still investigated. A recent study by Mills et al. [49] provided some clues: although no relation was found between $\mathrm{v}_{\mathrm{e}}$ and cell density, $\mathrm{v}_{\mathrm{e}}$ was positively correlated with mitotic activity. The results are counterintuitive: high mitotic activity is expected in tissue areas with higher cellular density, and not higher extracellular volume fraction. According to Mills et al., this suggests that $\mathrm{v}_{\mathrm{e}}$ does not reflect extracellular volume directly, possibly due to model flaws. Alternatively, high mitotic activity might not be associated with high cellular volume when malignant cells are very small or exhibit aberrant response to tumoral growth factors and contact inhibition. $\mathrm{v}_{\mathrm{e}}$ might also reflect microscopic necrotic regions or chaotic tissue architecture, which are also dominant features of higher-grade gliomas. In any case, $\mathrm{v}_{\mathrm{e}}$ has been found to be higher in HGG than in low-grade gliomas in other studies $[12,14,15,50]$ and was higher in enhancing tumors undergoing progression during concurrent radiation and chemotherapy [51]. Conversely, high $\mathrm{v}_{\mathrm{e}}$ of peritumoral edema was correlated with better OS [20]. This effect was hypothesized to be predictive: early blood-brain barrier disruption at the outskirt of tumor may facilitate immune response and delivery of chemotherapy agents.

Skewness of $\mathrm{v}_{\mathrm{e}}$ was also a significant predictor of PFS, but its clinical importance in the model was negligible (the associated HR was 0.94). Although this suggests that higher $\mathrm{v}_{\mathrm{e}}$ skewness might have a positive effect for PFS, the trend could easily change in a larger cohort. High positive skewness means that there are asymmetric outliers to the far right of the histogram, whereas high kurtosis indicates a sharper histogram peak around the mean values (such distribution could also be called leptokurtic) [52]. Higher skewness-resulting primarily from the contrasting vascular properties of the hypoxic/necrotic core and highly vascularized rim-reflects greater tumor heterogeneity and aggressiveness, thus possibly relating to worse prognosis. Persistent high skewness with a long tail to the right has been linked to worse treatment response in various non-brain tumors [52].

Higher IAUGC in our study was associated with worse PFS and OS on Kaplan-Meier analysis and was significantly higher in grade IV than in grade III gliomas. IAUGC is a simple and robust metric of perfusion, as it does not require a model or curve fitting. It is more resistant to poor fitting at extremely well or poorly vascularized regions, as well as during minute physiological fluctuations. IAUGC is calculated from the area under the contrast agent early uptake curve until a specified time (usually $60 \mathrm{~s}$ ) [39]. Similar to $\mathrm{K}^{\text {trans }}$, IAUGC could identify the highly vascularized and permeable tumor volume [39]. Indeed, IAUGC significantly correlated with $\mathrm{K}^{\text {trans }}$ in our study. On the downside, compared with $\mathrm{K}^{\text {trans }}$, physiological interpretation of IAUGC is limited.

In our study, $\mathrm{v}_{\mathrm{p}}$ was not a prognostic factor of OS or PFS. $\mathrm{v}_{\mathrm{p}}$ is the proportion of blood plasma volume per unit volume of tissue [53]. To this end, it reflects vascularization of tumor and could relate to more aggressive course, similar to rCBV of DSC perfusion. Nguyen et al. [26] have previously found $v_{p}$ to have a prognostic OS value for glioma patients in univariate, but not multivariate analysis, but it was not a significant prognostic factor in other studies [24]. We have found that only skewness and kurtosis of $\mathrm{v}_{\mathrm{p}}$ were significant negative predictors of OS in univariate analysis, even though the associated HRs were minimal ( 1.12 for $\mathrm{v}_{\mathrm{p} \_ \text {skew }}$ and especially 1.01 for $\mathrm{v}_{\mathrm{p} \_ \text {kurt }}$ ). As discussed before, high skewness signals higher heterogeneity and outliers with unusually high values, which are attributes of a more aggressive glioma. High kurtosis reflects a more peaked distribution of values, but is argued to be a less precise and a more difficult to interpret parameter.

$\mathrm{k}_{\mathrm{ep}}$ in our study was also a significant positive prognostic factor for OS in univariate analysis. $\mathrm{k}_{\mathrm{ep}}$ represents the reverse transfer of contrast material from the extravascular into the intravascular compartment. When the extravascular compartment $\left(\mathrm{v}_{\mathrm{e}}\right)$ is large, the transferred contrast agent tends to accumulate there, which results in delayed reverse transfer and decreased rate. Accordingly, higher $\mathrm{k}_{\mathrm{ep}}$ could be expected to have an opposite prognostic value than $\mathrm{v}_{\mathrm{e}}$. It was indeed observed in our study.

A number of perfusion parameters were significantly different for grade III vs. IV gliomas (Tables 1 and 2), with the best 
discrimination achieved by $\mathrm{K}_{90}^{\text {trans }}$ and $\mathrm{v}_{\mathrm{e}} 90$. These two parameters have already been shown to be different between grade III and IV [12, 16], between HGGs and LGGs [12, 14-16, 50], and between grade II and III oligodendrogliomas [54]. In our study, $\mathrm{k}_{\text {ep_90 }}$ was also significantly lower in grade IV gliomas. We have also investigated kurtosis and skewness of $\mathrm{K}^{\text {trans }}, \mathrm{v}_{\mathrm{p}}, \mathrm{v}_{\mathrm{e}}, \mathrm{k}_{\mathrm{ep}}$, and IAUGC as predictors of glioma grade. In a study of grade II and III astrocytomas and oligodendrogliomas, Falk et al. [55] found that $\mathrm{K}^{\text {trans }}$ skewness was higher for grade III gliomas. The difference was in fact below the accepted statistical significance $(P=0.07)$, but it was more significant than any other DCE parameter. In our study, grade III and IV gliomas were compared instead of grade II and III, and $\mathrm{K}_{\text {trans }}^{\text {skew }}$ for grade IV was unexpectedly lower than that for grade III. We have not found any study comparing $\mathrm{K}^{\text {trans }}$ skewness between grade III and IV gliomas, but we believe that our results may be biased due to the uneven distribution of non-enhancing tumors in grades III and IV. Significantly, more non-enhancing tumors were grade III $(P<0.001)$ and had higher $\mathrm{K}^{\text {trans }}$ skewness and kurtosis than grade IV $(P<0.05)$, possibly due to ROI including tumor and edema together, thus increasing heterogeneity. When bloodbrain barrier-disrupted (contrast-enhancing) gliomas of grade III and IV were side-by-side compared, no significant differences of skewness and kurtosis could be found $(P>0.05)$. This stresses the importance of precise tumor segmentation and separate analysis of contrast-enhancing fraction, necrosis, and edema for heterogeneity analysis.

IDH mutation status was a significant prognostic factor of PFS and OS on univariate analysis, while KPS was prognostic for OS. IDH mutation is a well-known positive prognostic factor for the malignant transformation and OS of low-grade gliomas [56, 57]. Previously, some DSC perfusion metrics in a study of $52 \mathrm{HGG}$ patients has been shown to be predictive of IDH mutation-IDH mutation-positive tumors had a more heterogeneous microenvironment [58]. We did not find any correlates of DCE perfusion and IDH mutation or MGMT methylation status, but this does not preclude discoveries in larger cohorts.

Our study is subject to a few limitations. Our sample size was relatively small $(N=69)$, which could explain why other than $v_{\mathrm{e}}$ perfusion parameters were not significant prognostic factors in multivariate analysis. We have tried to make the post-processing as standard as possible, but variation could arise when tumor area was delineated by hand. We could not evaluate interobserver variability formally as tumor delineation was performed only once. Another limitation was that we did not compare the prognostic value of DCE perfusion parameters with more established imaging biomarkers, such as rCBV or ADC. However, the primary goal of this study was to perform DCE perfusion parameter histogram analysis and investigate their direct relation with PFS and OS. To this end, we have succeeded in finding the most promising of them. Calibration of DCE perfusion prognostic value to other MRI biomarkers and subsequent optimal integration into standard imaging and evaluation protocol is left for future studies.

\section{Conclusion}

$\mathrm{V}_{\mathrm{e}}$ was the most consistent predictor of PFS and OS in high-grade glioma patients. $\mathrm{v}_{\mathrm{e} \_90}$ and $\mathrm{v}_{\mathrm{p} \_ \text {skew }}$ were negative, and $\mathrm{k}_{\mathrm{ep} \_90}$ was a positive prognostic factor for OS in univariate analysis, while $\mathrm{V}_{\mathrm{e}_{-} 90}$ was also a negative prognostic factor for PFS. $\mathrm{K}_{90}^{\text {trans }}$ and $\mathrm{V}_{\mathrm{e}} 90$ showed the best performance differentiating grade III and IV gliomas on ROC curve analysis.

Compliance with ethical standards We declare that all human and animal studies have been approved by our institutional review board and have therefore been performed in accordance with the ethical standards laid down in the 1964 Declaration of Helsinki and its later amendments. We declare that all patients gave informed consent prior to inclusion in this study.

Conflict of interest We declare that we have no conflict of interest.

Open Access This article is distributed under the terms of the Creative Commons Attribution 4.0 International License (http:// creativecommons.org/licenses/by/4.0/), which permits unrestricted use, distribution, and reproduction in any medium, provided you give appropriate credit to the original author(s) and the source, provide a link to the Creative Commons license, and indicate if changes were made.

\section{References}

1. Wen PY, Kesari S (2008) Malignant gliomas in adults. N Engl J Med 359(5):492-507. doi:10.1056/NEJMra0708126

2. Smoll NR, Schaller K, Gautschi OP (2013) Long-term survival of patients with glioblastoma multiforme (GBM). Journal of clinical neuroscience : official journal of the Neurosurgical Society of Australasia 20(5):670-675. doi:10.1016/j.jocn.2012.05.040

3. Theeler BJ, Yung WK, Fuller GN, De Groot JF (2012) Moving toward molecular classification of diffuse gliomas in adults. Neurology 79(18):1917-1926. doi:10.1212/WNL.0b013e318271f7cb

4. Hirai T, Murakami R, Nakamura H, Kitajima M, Fukuoka H, Sasao A, Akter M, Hayashida Y, Toya R, Oya N, Awai K, Iyama K, Kuratsu JI, Yamashita Y (2008) Prognostic value of perfusion MR imaging of high-grade astrocytomas: longterm follow-up study. AJNR Am J Neuroradiol 29(8):15051510. doi:10.3174/ajnr.A1121

5. Ducray F, El Hallani S, Idbaih A (2009) Diagnostic and prognostic markers in gliomas. Curr Opin Oncol 21(6):537-542. doi:10.1097/CCO.0b013e32833065a7

6. Saraswathy S, Crawford FW, Lamborn KR, Pirzkall A, Chang S, Cha S, Nelson SJ (2009) Evaluation of MR markers that predict survival in patients with newly diagnosed GBM prior to adjuvant therapy. J Neuro-Oncol 91(1): 69-81. doi:10.1007/s11060-008-9685-3

7. Law M, Young RJ, Babb JS, Peccerelli N, Chheang S, Gruber ML, Miller DC, Golfinos JG, Zagzag D, Johnson G (2008) Gliomas: predicting time to progression or survival with cerebral blood volume measurements at dynamic susceptibility-weighted contrast- 
enhanced perfusion MR imaging. Radiology 247(2):490-498. doi:10.1148/radiol.2472070898

8. Aronen HJ, Gazit IE, Louis DN, Buchbinder BR, Pardo FS, Weisskoff RM, Harsh GR, Cosgrove GR, Halpern EF, Hochberg FH, et al. (1994) Cerebral blood volume maps of gliomas: comparison with tumor grade and histologic findings. Radiology 191(1): 41-51. doi:10.1148/radiology.191.1.8134596

9. Russell SM, Elliott R, Forshaw D, Golfinos JG, Nelson PK, Kelly PJ (2009) Glioma vascularity correlates with reduced patient survival and increased malignancy. Surg Neurol 72(3):242-246 . doi:10.1016/j.surneu.2008.11.012discussion 246-247

10. Bonekamp D, Deike K, Wiestler B, Wick W, Bendszus M, Radbruch A, Heiland S (2015) Association of overall survival in patients with newly diagnosed glioblastoma with contrastenhanced perfusion MRI: comparison of intraindividually matched T1- and T2 (*)-based bolus techniques. Journal of magnetic resonance imaging : JMRI 42(1):87-96. doi:10.1002/jmri.24756

11. Mills SJ, Soh C, Rose CJ, Cheung S, Zhao S, Parker GJ, Jackson A (2010) Candidate biomarkers of extravascular extracellular space: a direct comparison of apparent diffusion coefficient and dynamic contrast-enhanced MR imaging-derived measurement of the volume of the extravascular extracellular space in glioblastoma multiforme. AJNR Am J Neuroradiol 31(3): 549-553. doi:10.3174/ajnr.A1844

12. Li X, Zhu Y, Kang H, Zhang Y, Liang H, Wang S, Zhang W (2015) Glioma grading by microvascular permeability parameters derived from dynamic contrast-enhanced MRI and intratumoral susceptibility signal on susceptibility weighted imaging. Cancer imaging : the official publication of the International Cancer Imaging Society 15 : 4. doi:10.1186/s40644-015-0039-Z

13. Cha S, Yang L, Johnson G, Lai A, Chen MH, Tihan T, Wendland M, Dillon WP (2006) Comparison of microvascular permeability measurements, $\mathrm{K}$ (trans), determined with conventional steady-state T1weighted and first-pass T2*-weighted MR imaging methods in gliomas and meningiomas. AJNR Am J Neuroradiol 27(2):409-417

14. Zhang N, Zhang L, Qiu B, Meng L, Wang X, Hou BL (2012) Correlation of volume transfer coefficient Ktrans with histopathologic grades of gliomas. Journal of magnetic resonance imaging : JMRI 36(2):355-363. doi:10.1002/jmri.23675

15. Awasthi R, Rathore RK, Soni P, Sahoo P, Awasthi A, Husain N, Behari S, Singh RK, Pandey CM, Gupta RK (2012) Discriminant analysis to classify glioma grading using dynamic contrastenhanced MRI and immunohistochemical markers. Neuroradiology 54(3):205-213. doi:10.1007/s00234-011-0874-y

16. Arevalo-Perez J, Peck KK, Young RJ, Holodny AI, Karimi S, Lyo JK (2015) Dynamic contrast-enhanced perfusion MRI and diffusion-weighted imaging in grading of gliomas. Journal of neuroimaging : official journal of the American Society of Neuroimaging. doi:10.1111/jon.12239

17. Jain KK, Sahoo P, Tyagi R, Mehta A, Patir R, Vaishya S, Prakash N, Vasudev N, Gupta RK (2015) Prospective glioma grading using single-dose dynamic contrast-enhanced perfusion MRI. Clin Radiol 70(10):1128-1135. doi:10.1016/j.crad.2015.06.076

18. Jia ZZ, Gu HM, Zhou XJ, Shi JL, Li MD, Zhou GF, Wu XH (2015) The assessment of immature microvascular density in brain gliomas with dynamic contrast-enhanced magnetic resonance imaging. Eur J Radiol 84(9):1805-1809. doi:10.1016/j.ejrad.2015.05.035

19. Jia ZZ, Gu HM, Zhou XJ, Shi JL, Li MD, Zhou GF, Wu XH (2015) The assessment of immature microvascular density in brain gliomas with dynamic contrast-enhanced magnetic resonance imaging. Eur J Radiol. doi:10.1016/j.ejrad.2015.05.035

20. Jensen RL, Mumert ML, Gillespie DL, Kinney AY, Schabel MC, Salzman KL (2014) Preoperative dynamic contrast-enhanced MRI correlates with molecular markers of hypoxia and vascularity in specific areas of intratumoral microenvironment and is predictive of patient outcome. Neuro-Oncology 16(2):280-291. doi:10.1093/neuonc/not148

21. Kickingereder P, Wiestler B, Graf M, Heiland S, Schlemmer HP, Wick W, Wick A, Bendszus M, Radbruch A (2015) Evaluation of dynamic contrast-enhanced MRI derived microvascular permeability in recurrent glioblastoma treated with bevacizumab. J NeuroOncol 121(2):373-380. doi:10.1007/s11060-014-1644-6

22. Verhoeff JJ, Lavini C, van Linde ME, Stalpers LJ, Majoie CB, Reijneveld JC, van Furth WR, Richel DJ (2010) Bevacizumab and dose-intense temozolomide in recurrent high-grade glioma. Annals of oncology : official journal of the European Society for Medical Oncology / ESMO 21(8):1723-1727. doi:10.1093/annonc/mdp591

23. Bisdas S, Smrdel U, Bajrovic FF, Surlan-Popovic K (2014) Assessment of progression-free-survival in glioblastomas by intratreatment dynamic contrast-enhanced MRI. Clin Neuroradiol. doi:10.1007/s00062-014-0328-0

24. Choi YS, Kim DW, Lee SK, Chang JH, Kang SG, Kim EH, Kim SH, Rim TH, Ahn SS (2015) The added prognostic value of preoperative dynamic contrast-enhanced MRI histogram analysis in patients with glioblastoma: analysis of overall and progressionfree survival. AJNR Am J Neuroradiol 36(12):2235-2241. doi:10.3174/ajnr.A4449

25. Burth S, Kickingereder P, Eidel O, Tichy D, Bonekamp D, Weberling L, Wick A, Low S, Hertenstein A, Nowosielski M, Schlemmer HP, Wick W, Bendszus M, Radbruch A (2016) Clinical parameters outweigh diffusion- and perfusion-derived MRI parameters in predicting survival in newly diagnosed glioblastoma. Neuro-Oncology. doi:10.1093/neuonc/now122

26. Nguyen TB, Cron GO, Mercier JF, Foottit C, Torres CH, Chakraborty S, Woulfe J, Jansen GH, Caudrelier JM, Sinclair J, Hogan MJ, Thornhill RE, Cameron IG (2015) Preoperative prognostic value of dynamic contrast-enhanced MRI-derived contrast transfer coefficient and plasma volume in patients with cerebral gliomas. AJNR Am J Neuroradiol 36(1):63-69. doi:10.3174/ajnr.A4006

27. Mills SJ, Patankar TA, Haroon HA, Baleriaux D, Swindell R, Jackson A (2006) Do cerebral blood volume and contrast transfer coefficient predict prognosis in human glioma? AJNR Am J Neuroradiol 27(4):853-858

28. Stupp R, Brada M, van den Bent MJ, Tonn JC, Pentheroudakis G, Group EGW (2014) High-grade glioma: ESMO Clinical Practice Guidelines for diagnosis, treatment and follow-up. Annals of oncology : official journal of the European Society for Medical Oncology / ESMO 25(Suppl 3):iii93-ii101. doi:10.1093/annonc/mdu050

29. Stupp R, Roila F (2008) Malignant glioma: ESMO clinical recommendations for diagnosis, treatment and follow-up. Annals of oncology : official journal of the European Society for Medical Oncology / ESMO 19(Suppl 2):ii83-ii85. doi:10.1093/annonc/mdn099

30. Stupp R, Tonn J-C, Brada M, Pentheroudakis G, Group ObotEGW (2010) High-grade malignant glioma: ESMO Clinical Practice Guidelines for diagnosis, treatment and follow-up. Ann Oncol 21(suppl 5):v190-v193. doi:10.1093/annonc/mdq187

31. Wen PY, Macdonald DR, Reardon DA, Cloughesy TF, Sorensen AG, Galanis E, Degroot J, Wick W, Gilbert MR, Lassman AB, Tsien C, Mikkelsen T, Wong ET, Chamberlain MC, Stupp R, Lamborn KR, Vogelbaum MA, van den Bent MJ, Chang SM (2010) Updated response assessment criteria for high-grade gliomas: response assessment in neuro-oncology working group. Journal of clinical oncology : official journal of the American Society of Clinical Oncology 28(11): 1963-1972. doi:10.1200/jco.2009.26.3541

32. Tofts PS, Kermode AG (1991) Measurement of the blood-brain barrier permeability and leakage space using dynamic MR imaging. 1. Fundamental concepts. Magn Reson Med 17(2):357-367

33. Orton MR, d'Arcy JA, Walker-Samuel S, Hawkes DJ, Atkinson D, Collins DJ, Leach MO (2008) Computationally efficient vascular input function models for quantitative kinetic 
modelling using DCE-MRI. Phys Med Biol 53(5):1225-1239. doi:10.1088/0031-9155/53/5/005

34. Parker GJ, Roberts C, Macdonald A, Buonaccorsi GA, Cheung S, Buckley DL, Jackson A, Watson Y, Davies K, Jayson GC (2006) Experimentally-derived functional form for a population-averaged high-temporal-resolution arterial input function for dynamic contrast-enhanced MRI. Magn Reson Med 56(5):993-1000. doi:10.1002/mrm.21066

35. Leach MO, Morgan B, Tofts PS, Buckley DL, Huang W, Horsfield MA, Chenevert TL, Collins DJ, Jackson A, Lomas D, Whitcher B, Clarke L, Plummer R, Judson I, Jones R, Alonzi R, Brunner T, Koh DM, Murphy P, Waterton JC, Parker G, Graves MJ, Scheenen TW, Redpath TW, Orton M, Karczmar G, Huisman H, Barentsz J, Padhani A, Experimental Cancer Medicine Centres Imaging Network Steering C (2012) Imaging vascular function for early stage clinical trials using dynamic contrast-enhanced magnetic resonance imaging. Eur Radiol 22(7):1451-1464. doi:10.1007/s00330-012-2446-x

36. Spampinato MV, Schiarelli C, Cianfoni A, Giglio P, Welsh CT, Bisdas S, Rumboldt Z (2013) Correlation between cerebral blood volume measurements by perfusion-weighted magnetic resonance imaging and two-year progression-free survival in gliomas. Neuroradiol J 26(4):385-395

37. Mangla R, Ginat DT, Kamalian S, Milano MT, Korones DN, Walter KA, Ekholm S (2014) Correlation between progression free survival and dynamic susceptibility contrast MRI perfusion in WHO grade III glioma subtypes. J Neuro-Oncol 116(2):325-331. doi:10.1007/s11060-013-1298-9

38. Heye T, Merkle EM, Reiner CS, Davenport MS, Horvath JJ, Feuerlein S, Breault SR, Gall P, Bashir MR, Dale BM, Kiraly AP, Boll DT (2013) Reproducibility of dynamic contrast-enhanced MR imaging. Part II. Comparison of intra- and interobserver variability with manual region of interest placement versus semiautomatic lesion segmentation and histogram analysis. Radiology 266(3): 812-821. doi:10.1148/radiol.12120255

39. Leach MO, Brindle KM, Evelhoch JL, Griffiths JR, Horsman MR, Jackson A, Jayson GC, Judson IR, Knopp MV, Maxwell RJ, McIntyre D, Padhani AR, Price P, Rathbone R, Rustin GJ, Tofts PS, Tozer GM, Vennart W, Waterton JC, Williams SR, Workman P (2005) The assessment of antiangiogenic and antivascular therapies in early-stage clinical trials using magnetic resonance imaging: issues and recommendations. Br J Cancer 92(9):1599-1610. doi:10.1038/sj.bjc.6602550

40. O'Connor JP, Jayson GC (2012) Do imaging biomarkers relate to outcome in patients treated with VEGF inhibitors? Clinical cancer research : an official journal of the American Association for Cancer Research 18(24):6588-6598. doi:10.1158/1078-0432.ccr-12-1501

41. Bernstein JM, Homer JJ, West CM (2014) Dynamic contrastenhanced magnetic resonance imaging biomarkers in head and neck cancer: potential to guide treatment? A systematic review. Oral Oncol 50(10):963-970. doi:10.1016/j.oraloncology.2014.07.011

42. Peng SL, Chen CF, Liu HL, Lui CC, Huang YJ, Lee TH, Chang CC, Wang FN (2013) Analysis of parametric histogram from dynamic contrast-enhanced MRI: application in evaluating brain tumor response to radiotherapy. NMR Biomed 26(4):443-450. doi:10.1002/nbm.2882

43. Kreisl TN, Zhang W, Odia Y, Shih JH, Butman JA, Hammoud D, Iwamoto FM, Sul J, Fine HA (2011) A phase II trial of single-agent bevacizumab in patients with recurrent anaplastic glioma. NeuroOncology 13(10):1143-1150. doi:10.1093/neuonc/nor091

44. Tofts PS, Brix G, Buckley DL, Evelhoch JL, Henderson E, Knopp MV, Larsson HB, Lee TY, Mayr NA, Parker GJ, Port RE, Taylor J, Weisskoff RM (1999) Estimating kinetic parameters from dynamic contrast-enhanced T(1)-weighted MRI of a diffusable tracer: standardized quantities and symbols. Journal of magnetic resonance imaging : JMRI 10(3):223-232
45. Aref M, Chaudhari AR, Bailey KL, Aref S, Wiener EC (2008) Comparison of tumor histology to dynamic contrast enhanced magnetic resonance imaging-based physiological estimates. Magn Reson Imaging 26(9):1279-1293. doi:10.1016/j.mri.2008.02.015

46. Pike MM, Stoops CN, Langford CP, Akella NS, Nabors LB, Gillespie GY (2009) High-resolution longitudinal assessment of flow and permeability in mouse glioma vasculature: sequential small molecule and SPIO dynamic contrast agent MRI. Magn Reson Med 61(3):615-625. doi:10.1002/mrm.21931

47. Aryal MP, Nagaraja TN, Keenan KA, Bagher-Ebadian H, Panda S, Brown SL, Cabral G, Fenstermacher JD, Ewing JR (2014) Dynamic contrast enhanced MRI parameters and tumor cellularity in a rat model of cerebral glioma at $7 \mathrm{~T}$. Magn Reson Med 71(6): 2206-2214. doi:10.1002/mrm.24873

48. Koh TS, Shi W, Thng CH, Kwek JW, Bisdas S, Khoo JB (2012) Interpretation and applicability of empirical tissue enhancement metrics in dynamic contrast-enhanced MRI based on a multiple pathway model. Phys Med Biol 57(15):N279-N294. doi:10.1088/0031-9155/57/15/N279

49. Mills SJ, du Plessis D, Pal P, Thompson G, Buonacorrsi G, Soh C, Parker GJ, Jackson A (2016) Mitotic activity in glioblastoma correlates with estimated extravascular extracellular space derived from dynamic contrast-enhanced MR imaging. AJNR Am J Neuroradiol 37(5):811-817. doi:10.3174/ajnr.A4623

50. Jia Z, Geng D, Liu Y, Chen X, Zhang J (2013) Low-grade and anaplastic oligodendrogliomas: differences in tumour microvascular permeability evaluated with dynamic contrast-enhanced magnetic resonance imaging. Journal of clinical neuroscience : official journal of the Neurosurgical Society of Australasia 20(8):1110 1113. doi:10.1016/j.jocn.2012.09.019

51. Yun TJ, Park CK, Kim TM, Lee SH, Kim JH, Sohn CH, Park SH, Kim IH, Choi SH (2015) Glioblastoma treated with concurrent radiation therapy and temozolomide chemotherapy: differentiation of true progression from pseudoprogression with quantitative dynamic contrast-enhanced MR imaging. Radiology 274(3):830-840. doi:10.1148/radiol.14132632

52. Just N (2014) Improving tumour heterogeneity MRI assessment with histograms. Br J Cancer 111(12):2205-2213. doi:10.1038/bjc.2014.512

53. Tofts PS, Wicks DA, Barker GJ (1991) The MRI measurement of NMR and physiological parameters in tissue to study disease process. Prog Clin Biol Res 363:313-325

54. Arevalo-Perez J, Kebede AA, Peck KK, Diamond E, Holodny AI, Rosenblum M, Rubel J, Gaal J, Hatzoglou V (2015) Dynamic contrast-enhanced MRI in low-grade versus anaplastic oligodendrogliomas. Journal of neuroimaging : official journal of the American Society of Neuroimaging. doi:10.1111/jon.12320

55. Falk A, Fahlstrom M, Rostrup E, Berntsson S, Zetterling M, Morell A, Larsson HB, Smits A, Larsson EM (2014) Discrimination between glioma grades II and III in suspected low-grade gliomas using dynamic contrast-enhanced and dynamic susceptibility contrast perfusion MR imaging: a histogram analysis approach. Neuroradiology 56(12):1031-1038. doi:10.1007/s00234-014-1426-Z

56. Cohen AL, Holmen SL, Colman H (2013) IDH1 and IDH2 mutations in gliomas. Current neurology and neuroscience reports 13(5): 345. doi:10.1007/s11910-013-0345-4

57. Zou P, Xu H, Chen P, Yan Q, Zhao L, Zhao P, Gu A (2013) IDH1/ IDH2 mutations define the prognosis and molecular profiles of patients with gliomas: a meta-analysis. PLoS One 8(7):e68782. doi:10.1371/journal.pone.0068782

58. Lee S, Choi SH, Ryoo I, Yoon TJ, Kim TM, Lee SH, Park CK, Kim JH, Sohn CH, Park SH, Kim IH (2015) Evaluation of the microenvironmental heterogeneity in high-grade gliomas with IDH1/2 gene mutation using histogram analysis of diffusion-weighted imaging and dynamic-susceptibility contrast perfusion imaging. J NeuroOncol 121(1):141-150. doi:10.1007/s11060-014-1614-Z 